all round sense to other methods but even in its most refined standards it is doubtful whether, alone, it serves fully the requirements of the long and severe operations now carried out in the abdomen. Success with inhalational anaesthesia demands a much higher degree of technical dexterity and more fundamental physiological and pharmacological knowledge on the part of the administrator than ever before. In the hands of the inexperienced there are many things that may go wrong and create dangers that are just as great, $\frac{\bar{\alpha}}{3}$

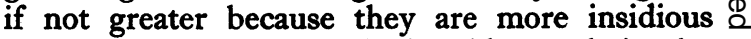
than those associated with the older, and simpler.. methods.

The observation so often made in the past that the choice of the anaesthetist is more important than the choice of anaesthetic is indeed truer today than ever for the scope for unintentional foolishness and possible disaster has widened considerably.

\title{
A SYSTEM OF ANAESTHESIA USING D-TUBOCURARINE CHLORDE FOR CHEST SURGERY
}

\author{
By T. Cfcil Gray, M.D., D.A., F.F.A., R.C.S. \\ Reader in Anaesthesia, University of Liverpool; Anaesthetist, Liverpool Chest Surgical Centre
}

The exciting and exploratory spirit which has become apparent of recent years in surgery would have been frustrated were it not that anaesthesia advanced contemporaneously. In no field has this spirit in surgery and this progress in anaesthesia been more in evidence than in the radical treatment of disease of the thoracic viscera. The pioneer work of Sauerbruch (1904) in Germany and the modern developments in America and Great Britain have produced an era in which surgical procedures of a gravity and extent hitherto considered impossible have become everyday events. The total or partial removal of a lung is now a rather less hazardous proposition than a major abdominal operation. Intra-cardiac surgery and the operative treatment of congenitally abnormal vascular channels are possible and new hope has been given to many patients hitherto doomed to starvation by removal and reconstitution of the diseased oesophagus. Moreover the surgery of tuberculous disease of the lungs has progressed far since the first thoracoplasty was performed in this country by Mr. H. Morriston Davies in 1912. It is the purpose of this paper to show how one of the most recent discoveries in anaesthesia is playing its part in these advances and materially contributing to successful surgery within the thorax. It is necessary first, however, to consider how the upset to a patient consequent upon the creation of an open pneumothorax can be offset by the anaesthetist.

Controlled respiration. In the presence of an open pneumothorax or when the pleura has been freed from the chest wall in thoracoplasty, certain mechanical disorders in the respiration are likely to occur. On the affected side the lung will collapse on inspiration and expand on expiration. This phenomenon has been described as "paradoxica respiration' and it results in a certain amount vitiated air passing from the collapsed to the normally expanded lung on each inspiration, and, if there is a sufficiently big respiratory excursion, it may lead to the spread of infected secretion into the bronchial tree and so from the diseased to the sound lung. Paradoxical movement of this kind will cause the mediastinum, if it is mobile, to swing away from the open side on inspiration and back on expiration. This ' flap' may interfere with the normal inspiratory filling of the opposite lung and by reducing the venous return to the heart result in sudden circulatory collapse.

For these reasons it is advisable during a thoracoplasty under general anaesthesia and essential in the presence of an open thorax, to control the respiration and avoid such irregular movements. Sauerbruch (1904) devised two methods of $\frac{7}{0}$ counteracting these undesirable effects both of which depend upon the production of a pressure $N$ gradient between, on the one hand, the atmosphere breathed by the patient and, on the other, the exposed lungs. In his ' Unterdruck Kammer' the head of the patient was occluded by an airtight rubber diaphragm from a room in which the remainder of his body together with the surgeon and his assistants were subjected to a pressure lower than atmospheric. The patient continued to breathe air at atmospheric pressure. Thus when the chest was opened there was no increase of 
pressure on the lungs and the normal respiratory pressure difference was maintained. Conversely the same effect was achieved by Sauerbruch's alternative method in which the patient's head was enclosed in an apparatus, the 'Ueberdrück Apparat,' in which the pressure was slightly above atmospheric. These original methods, however, were not altogether satisfactory and involved the use of complex and bulky apparatus. Meltzer (1909) and later Beecher (I940) achieved the same result by the continuous intra-tracheal insufflation of air and anaesthetic gases under a pressure sufficient to prevent collapse of the lung when the chest was opened. But this procedure facilitates the spread of infected material to healthy areas of the lungs and, according to Crafoord (1938), may result in a steadily increasing alveolar carbon dioxide tension.

The advent of closed circuit anaesthesia lead to the development of a method whereby the anaesthetist achieved perfect control of the respiration. The normal respiratory movements of the patient are completely abolished and the lungs are artificially inflated either by mechanical means as in Crafoord's spiro-pulsator, or by manual compression of the rebreathing bag of the anaesthetic apparatus. In this way the lungs are inflated and deflated rhythmically and paradoxical respiration which depends on active respiratory movement can no longer occur. An added advantage of this method of controlled respiration is that the movements of the lungs can be adapted to the requirements of the surgeon. Even this maneouvre, however, is not without disadvantages for it may produce certain undesirable physiological effects.

During apnoea the absence of a negative pressure within the thorax removes the respiratory venous pump mechanism and may lead to a deficient filling of the heart during diastole. Perhaps more important is the fact that the normal relationship between the respiration and the intra-pulmonary blood circulation is disturbed. In normal inspiration the alveolar blood capillaries are dilated by the negative intra-thoracic pressure and an effective and efficient interchange of gases between the blood and alveolar air is thus facilitated. When there is positive pressure on inspiration, as in complete control of the respiration with apnoea, these capillaries are flattened and many may be emptied. These effects have been investigated on animals by Humphries and his colleagues (1938) and they have shown that under similar conditions significant changes may result in both the cardiac output and pulmonary artery pressure. It is possible that circulatory changes brought about in this way may have an important bearing on the outcome of a critical case when there is only a small circulatory reserve.
It is, however, not always necessary to produce complete apnoea and paradoxical movement can be prevented in quiet respiration by exerting slight positive pressure on the rebreathing bag during inspiration. It seems likely that this degree of positive pressure will not balance completely the intra-thoracic negative pressure produced by inspiration, particularly on that side of the chest which remains closed and, therefore, the physiological upset will be less than when there are no active respiratory movements. This modified control of the respiration has been preferred except, as will be amplified later, when complete apnoea is desirable to assist the operative technique.

Inaccuracy in terminology is not uncommon and this latter maneouvre has been called by some ' assisted respiration.' However, in ordinary assisted respiration there is no attempt by the anaesthetist to control the respiratory movements ; they are simply augmented in order to overcome the depressant effects of, for example, Cyclopropane or d-Tubocurarine Chloride.

The use of $d$-Tubocurarine Chloride to provide respiratory control. In the past the impaired and quiet respiration necessary for control has been achieved by depression of the respiratory centre with heavy premedication and large doses of anaesthetic agents. Unfortunately, this resulted also in depression of the other medullary centres which are concerned with the maintenance of the circulation. Such 'depression anaesthesia' predisposes to shock and not infrequently resulted in toxic sequelae and prolonged periods of postoperative prostration. The same diminution of respiratory movement can be achieved by the use of very light narcosis and judicious doses of $d$ tubocurarine chloride.

d-Tubocurarine chloride is a pure alkaloid extracted from a tropical vine, the chondodendron tomentosum, which is found in the Amazonian jungles. For centuries Curare, the name given to extracts of this vine, was known only as a potent arrow poison and not until the time of Claude Bernard was its action scientifically investigated. Isolation of the pure alkaloid by King in 1935 made possible accurate pharmacological research into the properties of the drug and ultimately made safe its clinical application. d-Tubocurarine chloride produces paralysis of the voluntary striated muscles. This paralysis is peripheral in origin and is due to an interference at the neuromuscular junction with the conduction of the nerve impulse from the nerve to its muscle. The muscles of respiration being striated are affected. It is important to appreciate that paralysis is the only significant effect of an injection of d-tubocurarine chloride when it is administered in clinical dosage. It is therefore in a sense non-toxic, 
for the heart, liver, kidneys and other organs are unaffected. After the intravenous injection of normal doses the maximum-effect is developed in two to three minutes and it diminishes in intensity after twenty to thirty minutes. There is a cumulative effect, in that, after an initial dose, small increments will produce a marked effect.

The use of this substance to produce relaxation during anaesthesia for general surgery is now well established. Its application to chest anaesthesia although less apparent is no less fundamental and produces equally gratifying results. In thoracic surgery it permits the chest to be opened and the lung to be handled under light anaesthesia. The laryngeal and cough reflexes are depressed and the respiratory movements can be quietened and if necessary completely abolished. Because of the freedom from respiratory spasm very light anaesthesia can be maintained easily while ideal operating conditions are ensured. The principle of minimal narcotization with adequate curarization is the basis of the techniques which are to be described and which have been used in the Anaesthetic Section of the Liverpool Chest Surgical Centre during the past three years.

Action of physostigmine and neostigmine as antidotes to d-tubocurarine chloride. $\mathrm{d}$-Tubocurarine chloride is a powerful drug and its use is only justified if an equally powerful antidote is immediately available. Fortunately we have in physostigmine and neostigmine that antidote. The action of physostigmine was first observed by Pall (1900) who noted that normal respiration was resumed in curarized dogs after the intravenous administration of physostigmine salicylate. Koppanyi and Viveno (1944) showed that neostigmine methylsuphate (Prostigmine) had a similar anti-curare effect and was, in fact, dose for dose, twice as effective as physostigmine. The recent work of Burke, Linegar, Frank and McIntyre (1948) has confirmed these findings and placed beyond all doubt that up to the present neostigmine is the most effective drug in this respect. In the light of the humoral theory of neuro-muscular transmission physostigmine and prostigmine inhibit the action of cholinesterase and permit an unusually large concentration of acetylcholene at the myoneural junction. This may succeed in overcoming the inhibition by tubocurarine of the receptive substance of the muscle. A more recent observation is that these drugs cause a rise in excitability of the muscle by some other action and there appears to be good evidence that they prolong the action of a nerve volley on muscle or ganglion cells (Lloyd 1946). When curarization is complete neostigmine is less effective as an antidote and Trevan of the Wellcome Research Institute has shown by experiments on the rat's isolated phrenic nerve diaphragm preparation that after paralysis of the muscle with large doses of d-tubocurarine chloride its excitability to indirect stimulation cannot be restored by neostigmine in any dosage.

In clinical practice neostigmine is a very effective antidote to partial curarization and has been most useful in the work under consideration. The reason for the dissatisfaction shown by American writers with the effectiveness of this substance has been that they have used it in inadequate dosage. The dose of neostigmine which has been found most effectual is 3-5 mgm. administered with atropine gr. I/ Iooth to $\mathrm{I} / 5$ oth (0.65 mg.-I.3 mg.). The atropine is given to neutralize the undesirable parasympathomimetic effects. Whenever there is the slightest doubt concerning the complete recovery of the patient from the effects of tubocurarine, the anaesthetist should not hesitate to administer neostigmine, and, in fact, it is advisable as a routine following chest operations.

The preparation of the patient for operation. The adequate preparation of the patient before a thoracic operation plays a most vital part in ensuring a successful result. It is hardly necessary to stress that the patient must be seen before operation and the anaesthetist ensure that his preparation has been efficiently carried out ans that he himself is fully acquainted with the pare ticular problem on hand.

A very full and complete investigation of the cardiorespiratory function of the patient should be a routine in every major case and it should include a blood count, vital capacity and exercise tolerance estimations. Although not absolutely necessary a routine electro-cardiograph in patients over thirty years of age will provide occasional surprises and prevent some avoidable accidents. The paramount features of the pre-operative preparation can best be considered in relation to those types of major cases with which the thoracic anaesthetist is concerned.

Cases undergoing lung surgery have pulmonary disease requiring complete pneumonectomy, lobectomy, segmental resection of a lobe or some form of thoracoplasty. They are not infrequently in poor condition as a result of toxaemia and infection and may be producing large quantities of sputum. In such cases adequate physio-therapeutic preparation is of importance and should include the education of the patient in the art of breathing. Frequent vital capacity estimations should be made in order to assess improvement. If there is sputum production, a morning and evening postural drainage routine must be carried out and the quantity of sputum produced every twenty-four hours charted. In those cases which do not respond to postural drainage a course of 
penicillin inhalation is often very helpful. Complete otolaryngological toilet is necessary and a final careful check up should be made immediately prior to operation as to the presence of any acute naso-respiratory infection. In cases for thoracoplasty it is wise to make a radiological examination twenty-four hours prior to operation, in order to ensure that there has not been any unsuspected spread (Langton Hewer 1948).

Cases for cardiac surgery frequently have a very poor circulatory reserve. In the presence of actual decompensation the cardiac function must be improved as much as possible by rest in bed and adequate digitalization where it is required. Oedema may be a very prominent feature and in cases of constrictive pericarditis there may be, besides oedema, massive ascites and extensive pleural effusions. The effusions should be treated by repeated aspiration and a course of one of the mercurial diuretics before operation will often greatly improve the clinical picture. It is important to ensure that the chest is free from fluid on the day of operation as in these cases a rapid overnight accumulation may occur. Coincident bronchitis is common and should be treated by breathing exercises and if necessary penicillin. Arithmetical estimations of the cardiac efficiency such as that devised by Moot serve no useful purpose in these cases. Furthermore, exercise is often tolerated extremely badly by patients who are very suitable for and must undergo cardiac surgery. Perhaps the breath holding test of Sebrasez gives the best indication to the anaesthetist of the patient's cardiac reserve. The patient resting in bed takes a deep inspiration and holds it for as long as possible. Normally this period is thirty seconds, but anything less than fifteen seconds indicates a marked reduction in the cardiac or respiratory reserve. In dealing with these patients, however, no test can replace a good clinical acumen and a judgment based upon observation of the patient as a whole.

Cases for transthoracic gastric or oesophageal resection are not infrequently elderly and emaciated. A full investigation of their respiratory and cardio-vascular systems must always be carried out and an effort made to restore their constitution to a state approaching normal. A consideration of their plasma protein and blood count in conjunction with the haematocrit value will ensure control of the fluid and protein administration. It is necessary to stress that the haematocrit value should always be considered in determining the fluids to be administered, as in the presence of haemoconcentration, an anaemia may not be apparent and the fact not appreciated that whole blood rather than saline or plasma is the correct transfusion. If the patient can swallow fluids the preparation is easier, but if adequate oral fluid replacement is not possible, a rectal or intravenous routine must be adopted. In complete obstruction an attempt should always be made to dilate the stricture under anaesthesia sufficiently to take a Souttar's tube or allow a Ryle's tube to be passed so that a high protein fluid diet of ' fortified milk' can be given.

The anaesthetist must not allow himself to be too depressed by the pre-operative condition of these patients. Although by all the ordinary standards they would appear to have little chance of survival they not infrequently tolerate long operations remarkably well. It is a grave decision to refuse to give the only possible chance to one doomed to slow death by starvation.

Pre-medication. The rationale for pre-medication is that certain drugs are administered to prevent bronchial and salivary secretions during anaesthesia and to reduce the quantity of anaesthetic required. Atropinization is very important especially when d-tubocurarine chloride is to be used. If atropine is omitted, or if it is given too late for it to be effective before the induction of anaesthesia, the injection of tubocurarine may result in the production of large amounts of a sticky, glairy salivary secretion. This may cause laryngeal spasm and result in a critical situation. The second purpose of premedication is achieved by the administration of sedatives which allay apprehension, relieve pain and thus reduce the metabolism of the patient (Guedel 1937). Sedative drugs, such as morphia and scopolamine have also an action on the medulla and the reduction of the excitability of the respiratory centre by large doses of omnopon and scopolamine have in the past been an important part of the technique of controlled respiration. This depression is likely to be prolonged into the immediate post-operative period at which time it is most desirable to have a full respiratory function and active cough reflexes. Control of the respiration can now be achieved without such depression and heavy sedation is not necessary and is in fact definitely harmful. In Centres where an intravenous induction of anaesthesia is routine, patients, even quite small children, have little pre-anaesthetic apprehension. Very light premedication is desirable and is an important part of the technique advocated in this paper. For adults, morphia, gns. $\frac{1}{6}$ ( 1 I $\mathrm{mg}$.) and atropine gr. $1^{\frac{1}{5}}(0.4 \mathrm{mg}$.) is given at least one hour prior to the induction of anaesthesia. The dosage of atropine is the same for children, but that of morphia is modified according to age. If it is impossible to give the premedication at the proper time it should be given intravenously in the anaesthetic room. In such circumstances sedation is obviously not part of the function of 
the injection, but the morphia assists in reducing the amount of anaesthetic required and serves a useful purpose in a balanced technique of anaesthesia. On those occasions when a child has proved unco-operative and excited, rectal thiopentone ( $0.1 \mathrm{~g}$. per year) has been administered and given a most satisfactory and transient sedation.

Technique of anaesthesia. A standard anaesthetic arrangement and procedure for induction is used and slightly modified to suit the different types of operation. As the anaesthesia is mainly intravenous it is important to have a reliable and dependable method of making the injections and for these the three way tap originally described by Gray and Halton (1946) and its recent modification by Halton as described below have been found invaluable.

The tap (Figure I) is mounted on a small base moulded to the curve of the forearm and is easily strapped in position. The male end connects directly to a serum needle, size ten, and an intravenous drip is led to one of the two female inlets, the other being used to inject the solutions. The tap can be used either after the manner of a Gordh needle (Torston Gordh 1945) or in association with a continuous intravenous transfusion. In the former case when the tap is turned off between injections there can be no reflux of blood into the needle and blockage by clot is thus prevented. For longer procedures when a continuous drip of saline or blood should be used the arm is splinted before the apparatus is fixed in position. For convenience the arm opposite to the side of operation is the most suitable choice.

Induction of anaesthesia is carried out with dtubocurarine chloride and thiopentone. The dose of d-tubocurarine chloride is $15 \mathrm{mgm}$. for adults and $0.3 \mathrm{mgm}$. per kilo body weight for children and that of thiopentone $0.5 \mathrm{gm}$. for healthy adults with suitable reductions for children, the elderly and those with a poor cardiac reserve.

A test dose of d-tubocurarine chloride is first injected in order to detect any hypersensitivity to this substance (Gray and Halton 1948). In adults this is usually $5 \mathrm{mg}$. i.e. $\frac{1}{3}$ of the calculated induction dose. If after two minutes there is no sign of an unusual reaction, the remaining ro mgm. is injected followed by the thiopentone. Following this injection the lungs are immediately inflated two or three times with oxygen and a pharyngeal airway or endotracheal tube is introduced. Oral intubation is invariably performed with ease if the injections are given in this order and when a Macintosh laryngoscope is used. When the d-tubocurarine chloride is given before the thiopentone the maximum effects of both drugs are synchronized and provide excellent relaxation. The Macintosh laryngoscope facilitates the introduction of the tube by avoiding stimulation of that most sensitive area of the larynx, the posterior part of the epiglottis. The cheeks are packed with gauze to ensure a close and airtight fit of the anaesthetic facepiece. Where an endotracheal tube is employed the firmness of the lips and cheeks ensured by this pack enables the tube to be fixed in position by a piece of soft tubber tape passed round the occiput. (Figure 2). It is better to leave the connection between the endotracheal tube and the absorption canister free for if it is fixed, as for example by Hudson's harness, the endotracheal tube is apt to become kinked when the head is moved.

Anaesthesia is maintained with a mixture of 70 per cent. to 50 per cent. of nitrous oxide in oxygen, occasional injections of a 5 per cent. solution of Kemithal (I.C.I.) and increments of d-tubocurarine chloride as required. Kemithal is preferable for maintenance having a less depressant effect on the respiration and giving more rapid recovery than thiopentone (Halton). A Water's to and fro circuit is always employed. This apparatus is more reliable and has less possibility of leaks than the circle type of absorber. It permits a sensation of closer contact between the administrator and the patient which is most important when the depth of anaesthesia and the freedom of the airway must be assessed mainly? by the feel of the rebreathing bag. A long extension tube between the distal side of the absorption canister and the bag affords greater freedom of movement to the anaesthetist and provides less risk of disturbing the apparatus during the operation. Once the patient has been turned into the lateral position, for greater security the absorption canister may be fixed to the table.

To employ this technique successfully the anaesthetist should make a mental resolution to administer further doses of anaesthetic only when it is absolutely essential. After induction it is seldom necessary to inject more barbiturate until the surgeon is about to make his incision and then as little as $0.2 \mathrm{gm}$. of Kemithal will produce a quiet and relaxed patient. A further 10 $\mathrm{mg}$. of d-tubocurarine chloride will be required to control the respiratory movements before the chest is opened and after that control can be maintained by further doses of $2-5 \mathrm{mg}$. as required. Newcomers to this method of anaesthesia often have difficulty in deciding between the indications for the administrations of barbiturate and d-tubocurarine chloride, and there is no doubt that success depends largely upon a correct decision in this respect. d-Tubocurarine chloride provides respiratory control and relaxation. If the patient is resistant to inflation of the lungs, is straining, 


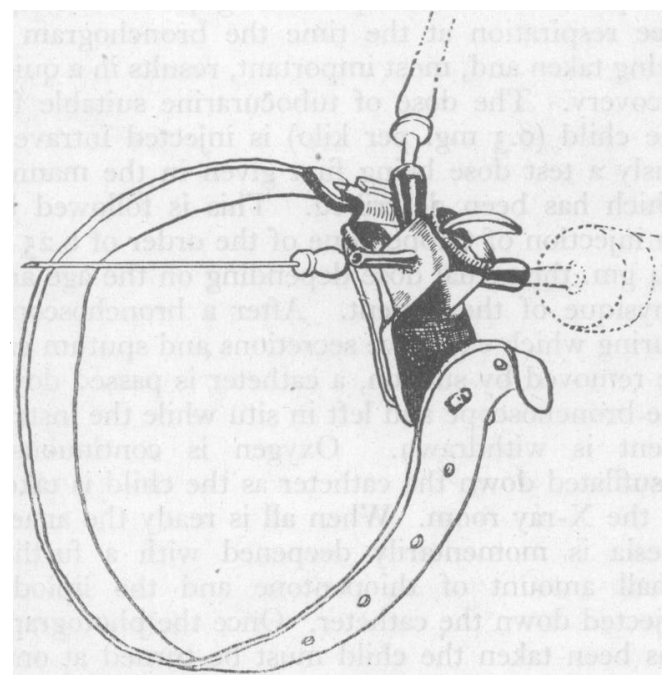

FIG. I.-Halton's modification of three way tap.

coughing, or there are ' bumpy' respiratory movements when the chest is opened, an injection of d-tubocurarine chloride will restore the situation. On the other hand more barbiturate is indicated when there is inadequate anaesthesia as evidenced directly by a slight movement of a limb or of the facial muscles and reflexly by a rising pulse rate. With experience and practice the discrimination is not difficult and niceness of decision will amply repay the careful observation of the patient which is necessary.

The indications for endotracheal intubation and bronchial tamponage or occlusion will be discussed when the particular technique for pulmonary operations is described, but a word must be said on the dangers of ' mechanical respiration.' Mechanical aids to assist or control respiration are popular in Scandinavia. Crafoord's (1938) modification of the Franckner Spiropulsator and Merck's Spiropulsator (1948) undoubtedly relieve the anaesthetist of a great deal of what might be considered monotonous work. It may be tedious to have to compress rhythmically a rebreathing bag for five hours and these machines free the anaesthetist to perform other useful functions, but they cannot replace trained hands. Automatic devices have no feeling or discrimination. A case was recently observed in which a patient undergoing thoracoplasty was artificially ventilated by mechanical means. Not only was the apex comparatively uncontrolled but an unsuspected spill over occurred and resulted in a spread of the disease. A disaster of this nature persuades one that these interesting mechanical achievements require much greater refinement before they can begin to compete with the interpretation of the pressure sensations by the human hands. The feel of the rebreathing bag helps the anaesthetist to determine not only the depth of anaesthesia and degree of curarization, but also the efficiency and freedom of the airway. It gives him warning of the collection within the bronchi of any sputum which requires removal by suction and enables him to adjust the movements of the lungs to the manipulations of the surgeon.

Before considering details there is one further point of principle which needs to be emphasized. In long traumatic and potentially shocking operations the circulatory blood volume should be maintained as it is lost, drop for drop. Under no circumstances should a blood transfusion be withheld until there is evidence of impending circulatory collapse. Neither is it advisable to depend upon the transfusions set up in the arm for blood replacement and a cannula should be inserted into the leg vein as soon as anaesthesia has been induced.

The standard technique which has been described has been adapted to all types of operations and the points peculiar and special to the individual thoracic procedures must now be discussed.

Endoscopy. Both oesophagoscopy and bronchoscopy can be performed under local surface analgesia. Even with adequate premedication, however, this is usually a very unpleasant experience for the patient. The administration of a small dose of thiopentone removes this objection, but when there is a long list, anaesthesia with d-tubocurarine chloride and thiopentone alone gives excellent results and is less time consuming.

The procedure and dosage is exactly that which

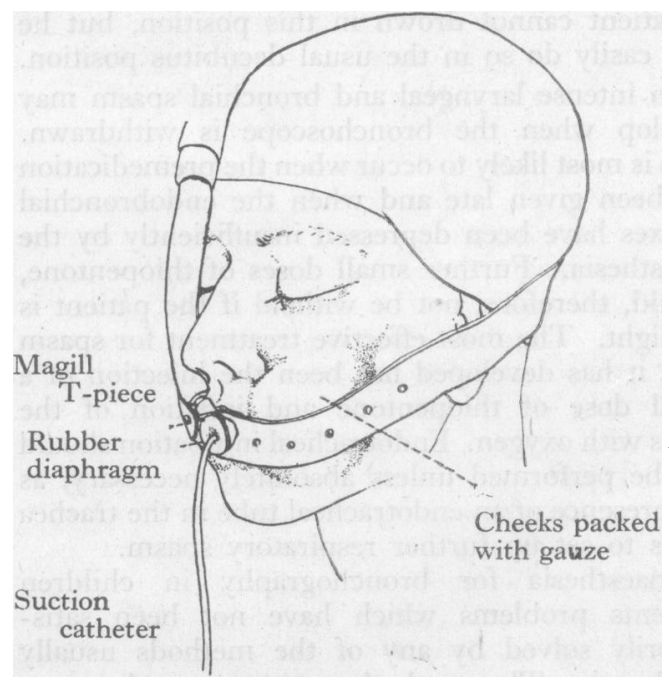

Fig. 2.-Method of fixing endotracheal tube. 
has been described for the induction of anaesthesia using the three way tap after the manner of a Gordh needle. There are a few points of detail in respect of oesophagoscopy and bronchoscopy which are important. Patients for oesophagoscopy are often poor risks and for the aged and cachectic a 2.5 per cent. solution of thiopentone should be used and the dosage reduced to $0.25 \mathrm{gm}$. with ro mg. of tubocurarine. A gum elastic catheter through which oxygen is continuously insufflated should be introduced into the trachea as the oesophagoscope is passed. It is not uncommon to encounter some resistance due to spasm of the inferior constrictor of the pharynx. This will usually relax after a few moments, but if it does not a small increment of thiopentone will enable the instrument to be passed with ease.

During bronchoscopy oxygen should be insufflated down the side tube of the bronchoscope. From the surgeon's point of view the conditions during the examination are usually ideal. A resistant patient may cough and strain a little but satisfactory control can be regained with a further small dose of thiopentone. When there is a great deal of sputum or blood in the bronchial tree it should be aspirated before the bronchoscope is withdrawn, following which the patient is turned at once on to the same side as his lesion with the head of the table lowered.

Under general anaesthesia patients with a considerable amount of sputum or a tendency to haemoptysis should be bronchoscoped in the head down position. If it is proposed to remove a foreign body or tumour endoscopically it is likely that a quantity of pent up secretion will be liberated and the head down position should be adopted before the endobronchial manipulation is started. A patient cannot drown in this position, but he may easily do so in the usual decubitus position.

An intense laryngeal and bronchial spasm may develop when the bronchoscope is withdrawn. This is most likely to occur when the premedication has been given late and when the endobronchial reflexes have been depressed insufficiently by the anaesthesia. Further small doses of thiopentone, should, therefore, not be witheld if the patient is too light. The most effective treatment for spasm once it has developed has been the injection of a small dose of thiopentone and inflation of the lungs with oxygen. Endotracheal intubation should not be performed unless absolutely necessary; as the presence of an endotracheal tube in the trachea tends to set up further respiratory spasm.

Anaesthesia for bronchography in children presents problems which have not been satisfactorily solved by any of the methods usually employed. The method at present under consideration has many advantages. It gives a smooth and pleasant induction permitting quiet and cough free respiration at the time the bronchogram is being taken and, most important, results in a quick recovery. The dose of tubocurarine suitable for the child ( $0.3 \mathrm{mg}$. per kilo) is injected intravenously a test dose being first given in the manner which has been described. This is followed by an injection of thiopentone of the order of 0.25 to $0.4 \mathrm{gm}$. the actual dose depending on the age and physique of the patient. After a bronchoscopy, during which excessive secretions and sputum can be removed by suction, a catheter is passed down the bronchoscope and left in situ while the instrument is withdrawn. Oxygen is continuously insufflated down the catheter as the child is taken to the X-ray room. When all is ready the anaesthesia is momentarily deepened with a further small amount of thiopentone and the lipiodol injected down the catheter. Once the photograph has been taken the child must be turned at once into the semiprone position, the head lowered and the catheter used again to insufflate oxygen. If there should be any respiratory depression or impairment of the cough reflex 1.0-2.5 mg. of neostigmine and atropine $0.65 \mathrm{mg}$. should be injected intravenously. Figure 3 shows a bronchogram taken using this type of anaesthesia.

Thoracoplasty. There has been a great deal of discussion concerning the relative merits of local and general anaesthesia for this operation. Many? of the objections to general anaesthesia, which have been raised, no longer apply. The performance of a nerve block of the chest wall is a lengthy procedure and entails no little discomfort for the patient. Very heavy pre-operative sedation with long acting drugs is required and the protective reflexes are thereby rendered less active for an indefinite period. Moreover, for second and third stage operations, the analgesia is difficult to produce and is not always satisfactory. It has to be helped out not infrequently by 'chloroform analgesia.'

The presence of the cough reflex throughout the operation has been postulated as an advantage of local anaesthesia ; yet illogically it is suggested that the vagus should be blocked to diminish this. same reflex (Joan Miller 1948). Coughing produces two effects. It is expulsive, but it also produces peripheral spread as can easily be demonstrated by a study of bronchograms taken after coughing. In the absence of a rigid chest wall during thoracoplasty the expulsive function of the cough is lost, but the peripheral spread remains and may do irreparable damage. The surgeon may manually control the apex when he tells the patient to cough, but such control can only be partially effective and an involuntary and unexpected cough is not infrequent and cannot be anticipated. 
Patients who are anaesthetized with barbiturate, nitrous oxide and tubocurarine have all their reflexes fully active at the end of the operation and most of them are able to talk before they leave the theatre. They have a cough reflex which is immediately effective. Their convalescence is as trouble free as any who are given a full local block.

In these cases the routine procedure for induction and maintenance of anaesthesia which has been described is adopted. Except where there is a large cavity and much sputum production an endotracheal tube should not be used for its introduction may result in slight trauma and the possible appearance of a new tuberculous focus in the larynx. In ' wet' cases, however, intubation and suction drainage must be the rule and the operation carried out in the Trendelenburg position.

When a pharyngeal airway only is used the prop originally described by Moreland Smith (1944) will support the jaw and be of great assistance. It is held in position by a Clausen's harness and, provided that the artificial airway is of adequate size and a good shape, perfectly satisfactory aeration can be maintained. After the induction of anaesthesia the line of incision is infiltrated with a I.2000 solution of amethocaine and, as the neuromuscular bundles are exposed, an intercostal block is performed with the same solution. This is of undoubted assistance as it allows the wound to be stitched at the end of the operation under extremely light narcosis and may reduce the operative shock.

The respiration must be controlled from the time that the parietal pleura of the apex has been freed from the chest wall. Complete apnoea is seldom required and a modified controlled respiration with a constant slight positive pressure (of the order of $4 \mathrm{~mm}$. of mercury) will keep the lung steady and greatly facilitate the work of the surgeon. The responsibility of the anaesthetist during these operations is very great indeed and nothing can do more tragic harm than a bad general anaesthetic. At no time must he lose a grip of the situation either in regard to the depth of anaesthesia or as to control of the lung. Too deep an anaesthesia may result in atelectasis of the lower lobe due to stagnation of secretion and uncontrolled movement of the apex may lead to spread of infected material to non-infected areas of the lung. The doses of the anaesthetic agents will depend on the type of case. As an indication of the maximum dosage which will be required in dealing with ex-servicemen the average for a first stage thoracoplasty has been of the order of $0.5 \mathrm{gm}$. of thiopentone, $0.25-0.5 \mathrm{gm}$. of kemithal and 20$45 \mathrm{mgm}$. of d-tubocurarine chloride.

Lobectomy and pneumonectomy. Although local analgesia has its advocates for thoracoplasty, general anaesthesia has become the accepted method for lung resection. Cyclopropane is generally considered the anaesthetic agent of choice for maintenance in these cases and it was undoubtedly this agent which first opened the door to modern thoracic surgery. Cyclopropane has many desirable properties from the point of view of the thoracic anaesthetist. It is nonirritant, controllable, and capable of producing anaesthesia in a very high concentration of oxygen. Furthermore the depression of respiration which accompanies its administration is of great assistance when the respiration has to be controlled. But the disadvantages of cyclopropane should make the anaesthetist welcome an alternative. Its explosibility and tendency to cause troublesome oozing in the wound no matter how efficient the ventilation are minor and tolerable defects, but more serious are its effects on the circulation. Recent studies in America (Dripps 1947) have lent authority to a clinical impression that cylcopropane is apt to give a false sense of security in regard to the circulatory condition of the patient. The blood pressure, pulse, colour and general condition of the patient may be perfectly satisfactory until the anaesthetic mask is removed at the end of the operation, when the patient may collapse suddenly with all the signs of 'shock' or gradually, over a period of half an hour, pass into a state of hypotension. This phenomenon has variously been attributed to a specific effect of cyclopropane, to the respiratory depression which attends its administration with consequent carbon dioxide retention and acidosis, and to closed circuit anaesthesia itself. But whatever its aetiology ' cyclopropane shock' is a very real entity. For these reasons the agent has been used only rarely and sparingly in the technique under consideration. For routine intra-thoracic procedures d-tubocurarine chloride with a barbiturate and nitrous oxide gives very satisfactory anaesthesia. The anaesthetic is controllable and permits of the use of the cautery in the chest. Furthermore the condition of the patient does not deteriorate at the close of the operation. It is usual to maintain the 50 per cent. mixture of nitrous oxide and oxygen by running in 500-600 ml. of each, gas per minute. This demands a certain small 'escape' from the closed circuit a feature which helps to avoid undue carbon dioxide retention (Dripps 1947). Cyclopropane is used only when it is considered that barbiturates will be tolerated badly, as in small children, the very elderly and those with evidence of myocardial weakness. There are occasions too when the administrator is unable to obtain just the perfect conditions which he requires and a little cyclopropane will tide him over a difficulty. When the bronchus is opened for example, prior to ligaturing, a few minutes of overventilation will usually pro- 
duce complete quietude ; but if this fails, it is often better to use a little cyclopropane than to give more tubocurarine, as the operation is generally nearing completion.

Control of the respiration, is, of course, essential from the time the pleura has been opened. The technique of this manoeuvre has been discussed but it should be pointed out that complete apnoea is required only during the dissection of an unusually difficult hilum or in freeing adhesions of the lung to the diaphragm. At other times it is better to maintain some respiratory movement. Some positive pressure should be maintained during inspiration until the chest has been closed so that the lung is kept fully expanded. Intercostal drainage is usual and after the chest has been closed the spigot should be inserted into the tube just after inspiration while positive pressure is exerted on the rebreathing bag. In this way expansion of the remaining lobe is ensured.

The control of secretion in 'wet' cases can be a difficult problem and the search for a satisfactory solution has fascinated every anaesthetist who has had to deal with such cases. There can be no routine, for every patient is a distinct and individual problem. Furthermore at a recent meeting at which this matter was discussed a speaker of some experience (Organe 1948) stated that he had yet to see an atraumatic bronchial occlusion, and with all the methods usually advocated this trauma is a factor which cannot lightly be dismissed.

Endobronchial anaesthesia can be used for pneumonectomies but it is debatable whether one lung anaesthesia is really desirable for this operation. It is rational to conserve the function of the useful part of the diseased lung as long as possible. The extra aerating surface thus maintained may well help to tide the patient over a long operation. In lobectomy on the other hand it would seem ideal to block off the diseased lobe, but none of the methods of bronchial occlusion are completely reliable and satisfactory. The Thompson type of suction occluder is very apt to slip out of position. More than once the balloon has been known to collapse during an operation and nothing is more disastrous than the failure of an occlusion upon which reliance has been placed. Perhaps the method of blind bronchial intubation described by Halton (1943) in which the balloon is held rigidly in position offers the most hope of a successful answer to this problem. It would, however, seem more prudent generally to depend on posture to prevent spill over and spread of infected material, and in cases with considerable secretion clamping of the bronchus by the surgeon at an early stage before the lobe is lifted will be of great assistance.

The majority of cases can be controlled by good physiotherapeutic preparation and during the operation suction drainage with $35^{\circ}$ of Trendelenburg. A plain endotracheal tube can be led out through a rubber diaphragm fitted in the facepiece and the secretion allowed to pass up the trachea round the tube into the facepiece as described by Beecher (Beecher, H. K., I940), but it is easier and more satisfactory to use a cuffed endotracheal tube with a Magill's T-piece and pass a suction catheter through the rubber cap. In this case care must be taken to ensure that the rebreathing bag is kept inflated during suction otherwise there is a danger of collapse of the lung. Where there is a large abscess cavity containing a fluid collection which has not been completely controlled by the preliminary postural drainage, pre-operative bronchoscopy and suction has been found most useful. Figure 3 shows such a cavity in a child aged $6 \frac{1}{2}$ years. The diseased lung was successfully removed using simple postural and suction drainage after a pre-operative bronchoscopy and toilet.

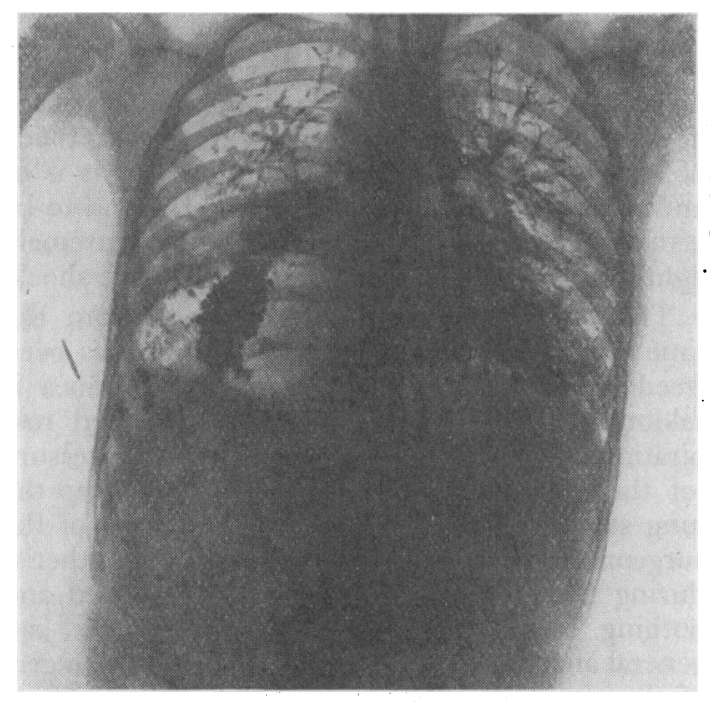

FIG. 3.-Bronchogram of child aged $6 \frac{1}{2}$ with a large infected cyst of the left lower lobe. Anaesthesia for the bronchogram was with thiopentone and d-tubocurarine chloride.

There remain, however, a limited number of cases for which these simple measures are inadequate. In the presence of a bronchopleural fistula positive pressure and controlled respiration is impossible as the inflated air simply passes into the pleural cavity. A similar difficulty may be encountered where a congenital cystic condition is associated with a non-return valve mechanism, (Gray and Edwards 1948). In these cases some 
form of endobronchial anaesthesia or occlusion is essential for satisfactory anaesthesia.

Trans-thoracic resections of the stomach and oesophagus call for minor modifications in technique. When the lesion is in the oesophagus, after the induction of anaesthesia an oesophagoscope is passed and oesophageal toilet carried out. During this procedure oxygen is continuously administered into the trachea through a gum elastic catheter in the manner already described. After completely clearing the oesophagus of food debris and secretions penicillin powder is insufflated. A 'Tampax' pack (attached to a long thread) is inserted to prevent the regurgitation of stomach and intestinal contents when continuity has been established between the oesophagus and stomach or jejunum. It may be possible to insert the cuffed endotracheal tube over the gum elastic catheter and thus avoid the need for another laryngoscopy which will require a deepening of the anaesthesia.

The induction and maintenance of anaesthesia is carried out in the standard manner. A trace of ether has been found of great value in these cases to reduce the amount of barbiturate which will be required. Ether has a curare-like action and when using it with d-tubocurarine chloride it should be remembered that there is a summation of both their effects at the myoneural junction. For this reason it is stated by some writers (Cullen 1944) that only $\frac{1}{3}$ of the dosage of tubocurarine should be injected when ether is the anaesthetic. Ether, however, is a toxic drug whereas d-tubocurarine is not, and theoretically it would seem more feasible and in practice it is conducive to better results to reduce the amount of ether and give the same dose of tubocurarine. The smallest concentration of ether which will give an 'ethereal' smell to the mixture should be used, for more than this will result in a prolonged recovery time.

During these operations there is not infrequently some deterioration in the patient's condition shortly after the chest has been opened. The blood pressure falls and the visible heart action appears weak. At this point it has been found of advantage to start an adrenalin drip as originally described by Frankis Evans (1944). Although a single injection of methedrine may produce a similar result adrenalin is preferable in that its effects are transient and, therefore, more controllable. After a short period it is usually possible to stop the adrenalin.

A feature of this method of anaesthesia is that no matter what the length of the operation the patient is never deeply anaesthetized and, as a result, is able in the majority of cases to talk before leaving the operating theatre. This state of consciousness is highly desirable as the action of the cardiac sphincter has been removed, and regur- gitation of fluid may occur from the stomach and be inhaled.

The surgical treatment of patients with heart disease has been made practicable by the work of Blalock in the United States and Brock in this country, and this paper would be incomplete without some reference to the technique of anaesthesia for this work. The general principles which have been postulated still hold and d-tubocurarine chloride is of the same value here as elsewhere. It has no action on the heart and it permits a very light plane of anaesthesia to be maintained easily and with minimal concentrations of drugs which in higher concentration may have a detrimental effect on the myocardium and conducting mechanism. It has been stated by many authorities that cyclopropane is contra-indicated because of the severe and frequent cardiac arrhythmias which are likely to occur when it is used. It is probable, however, that such irregularities are more frequent when cyclopropane is the sole agent and used in a concentration sufficient to depress the respiration. Undue irritability of the heart has not been observed when it has been employed with tubocurarine and a recent report (Rink 1948) suggests that used in this way it is the most suitable anaesthetic agent for the operative treatment of the tetralogy of Fallot. Some cardiac irregularities will always occur during manipulation of the heart and only if the arrhythmia becomes of threatening significance is it necessary to abandon cyclopropane and use ether. There is little doubt-that the intravenous injection of $3-5 \mathrm{ml}$. of I per cent. procaine or the application of a $\frac{1}{2}$ per cent. solution to the surface of the heart renders the organ less sensitive to mechanical stimulation.

Thiopentone or kemithal must be used with great caution when there is an impaired myocardium. There is evidence that these substances are direct myocardial depressants, and whilst cases with a patent ductus arteriosus may tolerate them well, a normal dose would certainly prove fatal in a case of constrictive pericarditis.

Patients with constrictive pericarditis have a feeble, thin and atrophic myocardium. They are usually oedematous and have enlargment of the liver, ascites and pleural effusions. They may have a marked degree of cyanosis and are.frequently orthopnoeic. Patients in this condition would call for a modification of most techniques: The following procedure has been found useful. After premedication with morphia and atropine, oxygen is administered through the anaesthetic mask for a few minutes prior to the induction of anaesthesia. Cyclopropane is then introduced at $400 \mathrm{ml}$. per minute with $500 \mathrm{ml}$. of oxygen until the patient is asleep. The usual test dose of $\mathrm{d}$ tubocurarine is given, after a pause it is followed 
by the injection of the remainder of the induction dose. Assisted respiration must be instituted at once to build up a good oxygen reserve which will allow for the quick introduction of an endotracheal tube. Anaesthesia is maintained with minimal quantities of cyclopropane or ether with increments of d-tubocurarine given as necessary to assist control of the respiration. In the less severe cases of decompensation it is possible to induce anaesthesia with 4-6 ml. of a 2.5 per cent. solution of thiopentone but great caution is necessary and full oxygenation before and during the injection should be ensured.

\section{Post-Operative Results}

It is becoming widely recognized that given good anaesthesia the results following any surgical procedure depend less upon the technique or agent used than was at one time considered probable. In thoracic work the efficiency of the pre-operative physiotherapy, medical preparation and the standard of post-operative nursing are variable factors making it difficult to compare the results obtained in different centres. Even the degree of humidity of the atmosphere in the wards may influence the post-operative convalescence of these patients.

The essential prerequisites of any anaesthesia for this work are that it should permit control of the respiration, result in as little toxic upset of the patient as possible and permit a patient at the end of the operation to be co-operative and able to cough and breathe efficiently. When small doses of the anaesthetic agents are combined with adequate dosage of d-tubocurarine in the manner which has been described the patients are routinely awake at the close of the operation and not infrequently they have been able to converse intelligently as they leave the theatre perhaps following a five-hour oesophagectomy. Such co-operation materially facilitates the post-operative nursing and removes the danger of the aspiration of vomit or secretion. There need be no apprehension that the respiration will be depressed after tubocurarine when it is used in reasonable dosage and added safety is provided by the routine injection of an adequate dose of neostigmine.

Nausea and vomiting has been rare following thoracotomy but it still occurs after thoracoplasty. It is of interst that vomiting persists even when local analgesia is used (Joan Miller 1948). The vomiting has been attributed to the morphia given in premedication but this seems an unlikely explanation in view of its comparative infrequency after other thoracic procedures. It may well be due to some vagal imbalance resulting from collapse of the chest wall.

There is possibly an increased frequency of retention of urine when d-tubocurarine has been employed (Gray 1948). In the present series this has not been unduly troublesome and the retention $\mathrm{C}$ has usually responded to injections of carbachol. $\stackrel{ }{\Rightarrow}$ One patient, however, did not micturate naturally $\stackrel{\overrightarrow{\vec{\rho}}}{\overrightarrow{0}}$ for seven days following a lobectomy.

During 1945 and 1946 a sufficient number of $\frac{\bar{\sigma}}{\bar{O}}$ operations for thoracoplasty were performed to $\frac{\bar{s}}{\frac{\sigma}{a}}$ permit numerical comparison with other series. $\stackrel{\mathbb{Q}}{\Omega}$ In the following analysis the results will be compared with the figures quoted by Joan Miller $(1948)$ ( for a very comparable series of cases in which local. analgesia was used (Table $r$ ). There have been

TABLE I

\begin{tabular}{|c|c|c|c|c|c|c|c|}
\hline & Cases & $\begin{array}{c}\text { Ist } \\
\text { stage }\end{array}$ & $\begin{array}{l}\text { 2nd } \\
\text { stage }\end{array}$ & $\begin{array}{c}3 r d \\
\text { stage }\end{array}$ & Ant. & Rev. & $\begin{array}{l}\text { Apico- } \\
\text { lysis }\end{array}$ \\
\hline $\begin{array}{l}\text { Parenchymatous } \\
\text { disease }\end{array}$ & & 18 & 88 & 36 & 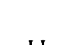 & ? & 16 \\
\hline $\begin{array}{l}\text { Basal } \\
\quad \text { operations . . }\end{array}$ & 5 & I & 5 & 5 & 5 & & \\
\hline Empyema & 9 & 9 & 8 & 5 & & & \\
\hline $\begin{array}{l}\text { Comparative } \\
\text { series (Joan } \\
\text { Miller I948) }\end{array}$ & 204 & 180 & & 172 & 8 & I 3 & $15385 \%$ \\
\hline
\end{tabular}

Particulars of thoracoplasty operations performed r945-1946.
The comparative series is that quoted by Joan Miller (1948) carried out under local analgesia.

in this series six deaths within three months of operation giving an operative mortality of $3.6 \overline{0}$

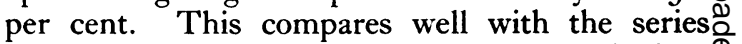
under local analgesia in which twelve deaths in $a \propto$ similar period gave a mortality of 5.3 per cent. $\overrightarrow{\overrightarrow{0}}$ The cause of death in the following series of cases 3 was as follows :-

(I) Pulmonary embolus. This patient developed? a femoral thrombosis four weeks after a응 second stage operation and died in the $\frac{3}{.}$. seventh week. The presence of a large pul- $\frac{0}{3}$ monary embolus was confirmed at post mortem.

(2) Acute tuberculous pneumonia of the same side following a first stage without apicoly-윽 sis. The cause of death was confirmed at $\frac{D}{0}$ autopsy.

(3) Acute bilateral tuberculous broncho-pneu- $N$ monia, six days after a first stage operation $N$ with apicolysis. Confirmed at autopsy. N This was the only case of contra-lateral spread in the present series.

(4) Coronary thrombosis. This patient col- $\frac{0}{\mathbb{C}}$ lapsed and died eight hours after a first stage operation with apicolysis. Confirmed at autopsy.

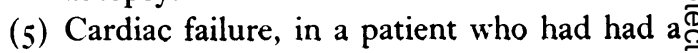


13 years history of tubercle. She made a good recovery after a first stage thoraco-

TABLE 2

Morbidity After First Stage Thoracoplasty Sufficient to CAISE DELAY OF SECOND STAGE

\begin{tabular}{|c|c|c|c|c|c|}
\hline Delay & & $\begin{array}{l}\text { weeks } \\
\text { N.A. }\end{array}$ & A. $\stackrel{\text { weeks }}{\text { N.A. }}$. & $\left(\begin{array}{l}4 \text { weeks } \\
A .\end{array}\right.$ & $\begin{array}{l}\text { Indefinite } \\
\text { A. N.A. }\end{array}$ \\
\hline $\begin{array}{l}\text { Poor general condition } \\
\text { Bronchitis } \\
\text { Consolidation base } \\
\text { Atelectasis.. }\end{array}$ & $\begin{array}{l}4 \\
1 \\
3 \\
1\end{array}$ & 2 & $I$ & & $3 \mathrm{IEm}$ \\
\hline 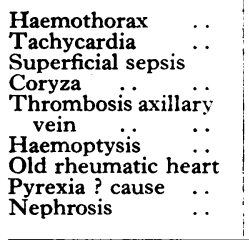 & $\begin{array}{l}3 \\
2 \\
1 \\
1\end{array}$ & 7 & I & nchi & \\
\hline
\end{tabular}

35 delayed out of ${ }_{15} 8$ first stages $-22^{\circ}, 07$ in non-apicolysis and 28 in apicolysis.

A-apicolysis. N.A.-non-apicolysis.

plasty. After her second stage she left the theatre in good condition and recovered from her anaesthetic. Three hours later she collapsed suddenly and died with all the signs of cardiac failure. There was no post mortem examination.

(6) Unknown cause. This man developed respiratory distress for no apparent reason towards the end of a first stage operation with apicolysis. The respirations were gasping in type and continued so for six hours when he died. His blood pressure at the close of the operation was $175 / 100$ and he had a very forcible bounding pulse of eighty beats per minute, which was suggestive of a cerebral lesion. Nothing was found at autopsy.

A useful indication of the morbidity following thoracoplasty is afforded by the number of patients who are fit for their subsequent stages within the usual period of two weeks. Tables 2 and 3 show the number of cases which had to be delayed after their first and second stages. Table 4 shows the total morbidity after second stage operations.

Atelectasis following thoracoplasty. There were I3 (3.6 per cent.) cases of atelectasis of the lower

TABLE 3

Morbidity After Second. Stage Thoracoplasty Sufficient To Cause Delay of Third Stage

\begin{tabular}{|c|c|c|c|c|}
\hline Delay & $\begin{array}{l}2 \text { weeks } \\
\text { A. } \quad \text { N.A. }\end{array}$ & A. $\stackrel{4 \text { weeks }}{\text { N.A. }}$ & $\begin{array}{l}4 \text { weeks } \\
A .\end{array}$ & $\begin{array}{l}\text { Indefinite } \\
A . \quad N . A .\end{array}$ \\
\hline $\begin{array}{lll}\text { Pyrexia } & \ldots & \ldots \\
\text { Sepsis } & \ddot{j} & \\
\text { Poor general condition } \\
\text { Haematoma }\end{array}$ & 1 & (Basal) $^{I}$ & & \\
\hline
\end{tabular}

TABLE 4

Morbidity After Second Stage Operations

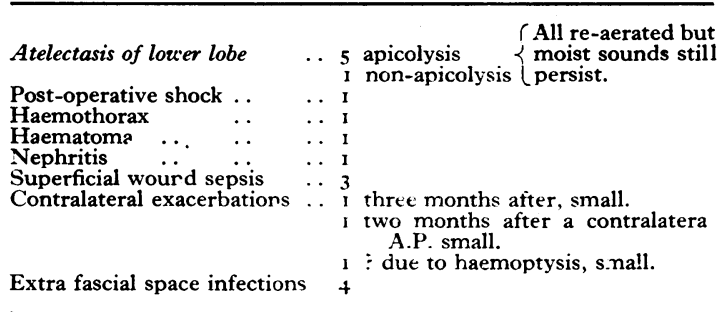

lobe following thoracoplasty in this series and $2 \mathrm{I}$ ( 5.5 per cent.) in the series done under local analgesia. Seven ( 4.4 per cent.) of the cases under general anaesthesia followed first stage operations and 6 (4.0 per cent.) occurred after second stages. Following local analgesia 9 (5.9 per cent.) occurred after upper stages and 12 after second stages. The number of second stages in the latter series is not known as the figure given (172) combines second and third stage operations.

This present series and that with which it is compared are not large in numbers but they are comparable, in that similar operations were performed under conditions which were not dissimilar.

These results would seem to indicate fairly clearly that light general anaesthesia with $d-$ tubocurarine chloride is as safe as local analgesia for thoracoplasty operations. It is certainly more pleasant for the patient and the surgeon, and less time consuming for the anaesthetist.

Results following lung resection. The details of the lung resections which have been performed in the years 1946-1947 at the Liverpool Chest Surgical Centre under this form of anaesthesia are shown in Table 5 .

Following these i 6 operations there have been five deaths within four months giving a case mortality of 4.3 per cent.

TABLE 5

LUNG RESECTIONS 1940 - 1947

$\begin{array}{lllr}\text { Lobectomy : } & \begin{array}{l}\text { Bronchiectasis } \\ \text { Carcinoma }\end{array} & \ldots & 82 \\ \text { Cyst of lung } & \ldots & 3 \\ \text { Abscess } \ldots & \ldots & 1 \\ \text { Tuberculosis } & \ldots & 3 \\ \text { Adenoma } & \ldots & \frac{1}{1} \\ & & & 92 \\ \text { Pneumonectomy : } & \text { Bronchiectasis } & \ldots & 13 \\ & \text { Carcinoma } & \ldots & 10 \\ & \text { Adenoma } & \ldots & 1 \\ & & & 24\end{array}$

(I) Pulmonary oedema. This man aged fortythree was in poor condition before his operation and died 29 hours after a difficult pneumonectomy for carcinoma. 
Shortly after his operation he showed signs of oedema of the remaining lung and his condition gradually deteriorated. A subsequent section of the removed lung revealed that he had tubercle in addition to carcinoma.

(2) Cerebral catastrophe. This patient aged sixty-five years, died following pneumonectomy for carcinoma. His condition was poor at the end of the operation which was difficult and prolonged. The next day he was found to have hemiplegia and he collapsed suddenly and died on the evening of the second day after operation. There was no post-mortem.

(3) Surgical emphysema which developed 24 hours after a pneumonectomy for bronchiectasis. The chest, arms, neck and possibly the mediastinum were involved and despite the repeated aspiration of air from his chest his condition gradually deteriorated. Permission was not granted for a post-mortem examination.

(4) Caseous tuberculous pneumonitis in association with renal and cardiac failure. This man aged forty-nine years, had undergone a left upper lobectomy for a lesion considered to be a tuberculoma, however, he had much more extensive disease than had been thought and after his operation he developed tuberculous pneumonitis of the lower lobe and later an acute form of nephritis and cardiac failure. He died four months after operation.

(5) Anoxia due to a sudden intra-bronchial haemorrhage and spill-over of thick tenacious sputum. This patient suffered from recurrent haemoptyses and had a chronic abscess of the right lower lobe. During the early manipulation and freeing of the lobe haemorrhage into the bronchus occurred and a great deal of tenacious secretion spilt over into the bronchial tree. Despite immediate bronchoscopy and suction the patient succumbed. The use of a suitable and reliable bronchial occluder would probably have avoided this accident. A preoperative bronchoscopy, however, was not performed and it seems likely that the operation was not carried out in the head down position.

Owing to the many factors involved it is difficult to obtain a reliable assessment of the results following lung resection and figures for comparison are not easy to find. It is hoped that such an analysis together with the results which have been obtained in other types of thoracic procedures (Table 6) will be the subject of a later communication.
TABLE 6

Other Operations Performed at The Liverpool Chest Surgical CENTRE, 1946-1947

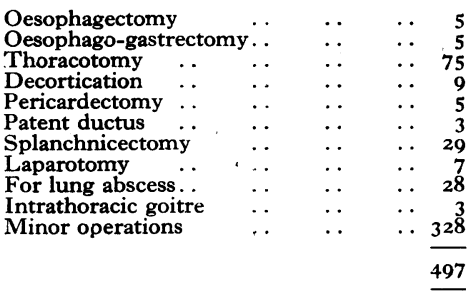

\section{Summary}

The methods of controlled respiration are reviewed and the role of d-tubocurarine chloride in thoracic surgery is discussed. The preparation $A$ and anaesthetization of patients for various thoracic $N$ procedures is detailed and the results following or 363 thoracoplasties discussed in detail together $\vec{A}$ with the operative mortality in 116 lung resections.

I am most grateful to Mr. H. Morriston Davies, $\vec{O}$ F.R.C.S., for his unfailing help and encouragement and to Mr. F. Ronald Edwards, F.R.C.S., O for much advice and assistance with this paper $\mathbb{\mathbb { Q }}$ and for the detailed results following thoracoplast $\overrightarrow{0} \overrightarrow{0}$

The skill and originality of my colleague anaes thetists at the Liverpool Chest Surgical Centre Dr. John Halton and Dr. Joseph E. Esplen, andt their permission to include cases anaesthetized by them have made this paper worthwhile.

Lastly I owe a special word of gratitude to Miss E. S. N. Fenton, my registrar, for statistical research.

\section{BIBLIOGRAPHY}

BEECHER, H. K. (1940), F. of Thoracic Surgery, 10, 202.

BURKE, J. C., LINEGAR, C. R., FRANK, M. N., MCINTYRE, A. R. (1948), Anesthesiology, 9, 251 .

CRAFOORD, C. (1938), On the Technique of Pneumonectomy in Man. Stockholm. 61. Tryckeri Aktiebolaget Thule also Asta Chirurg. Scand. 54. (Supplement).

CULLEN, S. C. (1944), Anesthesiology, 5, 166.

DRIPPS, R. D. (r947), Anesthesiology, 8, 15.

EVANS, Frankis (1944), Lancet, 1, 15 .

GORDH. T. (1945), Anesthesiology, 6, 258.

GRAY, T. C. and EDWARDS, F. R. E. (1948), Thorax. In the press.

GRAY', T. C. and HALTON, J. (1946), B.M. . ., 2, 293.

GRAY, T. C. and HALTON, J. (1948), B.M.J., I, 784 .

GRAY, T. C. (1948), Proc. Roy. Soc. of Med., 41, 559 .

GUEDEL New York, p. 61.

HALTON, J. (1943), Lancet, I, 12.

HEWER, C. Langton (1948), Annals of the Roy. Coll. of Surgeons, N HUMPHRIES, G. H., MOORE, R. L., MAIER, H. C. and APGAR, V. (1938), 7 . of Thoracic Surgery, 7,438 .

KING, H. (1935), F. Chem. Soc. Pt. 2, 1381 .

KOPPANYI, T. and VIVINO, A. E.'(1944), Science, roo:474. N

LLOYD, D. P. C. (1946), In Howell's Textbook of Physiology rev.

by Fulton, Saunders, p. 133 .

MELTZER (1909), Fourn. of Exper. Med., 2, 622.

MILLER, J. (1948), Tubercle, 29, 121.

MORCH, E. T. (1948), Anaesthesia, 3, 4.

ORGANE, G. (1948), Brit. Med. Fourn., 1, 9 r.

PALE, J. (1900), Centralbl. f. Physiol., 10.

RINK (1948), Brit. Med. 尹ourn., 1, 91 .

SAUERBRUCH (1904), Mittheilungen aus den Grenzegebieten der $\vec{D}$

Medizin und Chirurgie, $13,399$.

SMITH, J M. (1944), Brit. Med. Э., 2, 820.

TREVAN, J. (r946), Personal communication. 